\section{The use of anterior gold basket crowns among remote Amazonian communities}

\author{
F. Jamil ${ }^{1}$
}

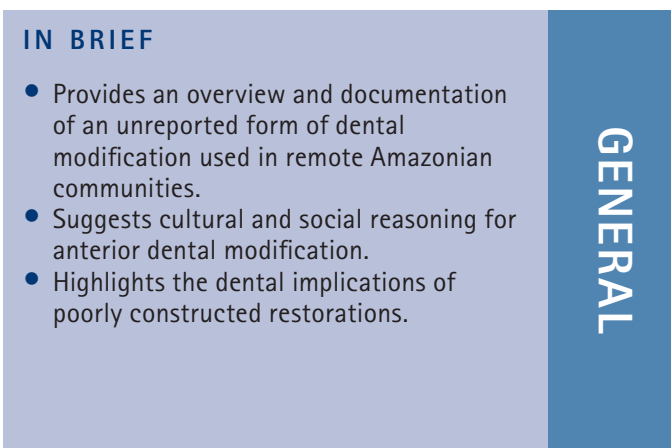

\begin{abstract}
Anterior gold basket crowns are a type of restoration worn among remote Amazonian communities, primarily placed for cosmetic and social reasons. There is very minimal literature reporting the use of these restorations in present day communities. This form of dental modification is outlined in the following article, as well as documenting various cases that show the biological implications that these unconventional restorations can have on healthy teeth.
\end{abstract}

\section{INTRODUCTION}

The use of anterior gold restorations has been practiced for many generations by various communities across the world. While the move to tooth coloured restorations for anterior teeth has been widely adopted by western urban populations, there are still many communities for whom anterior gold restorations play a significant role in identity and social status. The Amazon is made up of many remote tribal communities that lack access to adequate healthcare. Oral health is poor with no access to fluoride, dental hygiene aids and a generally poor diet. Due to a lack of material possessions, personal wealth is often portrayed through physical appearance. Dental modification is one way by which they achieve this. This article focuses on the use of these basket crowns worn by the remote communities of the Amazon.

\section{HISTORICAL USE OF ANTERIOR GOLD RESTORATIONS}

Historically the use of full coverage anterior gold dental prostheses for cosmetic purposes has been reported as far back as the seventh century BC, with Etruscan gold appliances being created out of flat gold bands. ${ }^{1}$ Similarly, Wynbrandt reported the covering of teeth with thin plates of gold by the people of Karbandan, Southern China. ${ }^{2}$ These historical appliances usually covered the whole tooth surface, which is

'DF2 Oral and Maxillofacial Surgery, Royal Surrey County Hospital, Egerton Rd, Guildford, GU2 7XX Correspondence to: Fahad Jamil

Email: fahadjamil88@gmail.com

\section{Refereed Paper}

Accepted 10 January 2014

DOI: 10.1038/sj.bdj.2014.297

${ }^{\circ}$ British Dental Journal 2014; 216: 475-476 not the case with gold basket crowns where partial coverage is employed. The only other documentation of basket type crowns being used is in the tribal communities of Borneo. ${ }^{3}$

\section{GOLD BASKET CROWNS}

Basket crowns are placed on anterior teeth, either on single (Fig. 1) or multiple teeth (Fig. 2). The term 'basket' arises from the fact that unlike conventional crowns where full coverage is adopted, they possess a window, which exposes most of the labial surface of the underlying abutment. This leaves a decorative border of gold around the tooth. The material used in constructing these basket crowns is 'Oropel' (latten brass), which serves as an inexpensive imitation of gold. The cost of these restorations is between 50-80 PEN (£11-17). Each restoration is constructed in a similar way to conventional crowns, where impressions are made after preparation of the tooth, followed by a technician fabricating the restoration on the cast. A luting cement is then used to fit the crown. The provision of these restorations is by 'back street' dentists who lack restorative knowledge and skill. The biological impact of these gold basket crowns is evident through destruction of healthy tooth tissue, secondary caries and plaque retention leading to periodontal consequences. The following cases highlight these unfortunate outcomes.

\section{CASES}

Figure 3 shows gold basket crowns placed on both upper central incisors. The extensive reduction of healthy enamel on the labial surface is evident, resulting in a coarse and weakened surface more prone to acid dissolution. The metal shine through from the palatal surface produces a dull appearance of

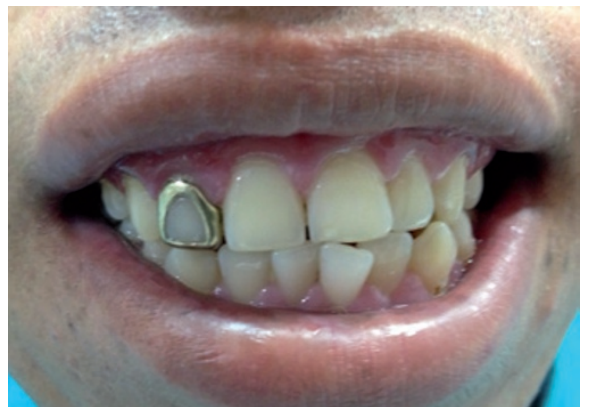

Fig. 1 Basket crown placed on single anterior tooth

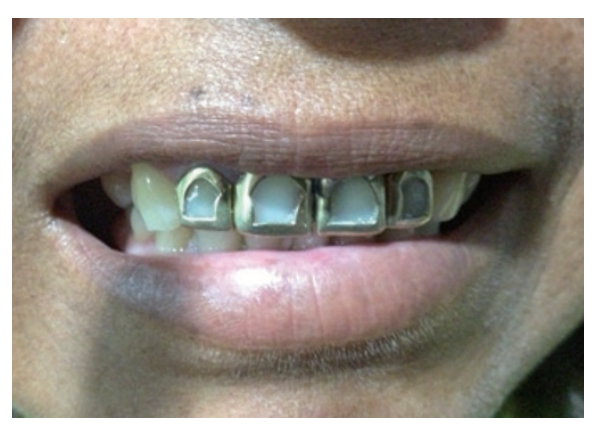

Fig. 2 Basket crowns are placed on multiple anterior teeth

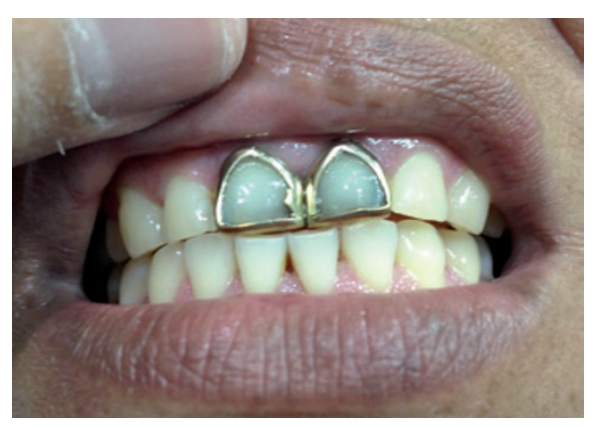

Fig. 3 Gold basket crowns placed on both upper central incisors

the teeth (a verified unintentional aesthetic effect). Early tooth surface loss on the opposing lower incisors is present. 
A poor labial emergence profile combined with suboptimal oral hygiene has resulted in gingivitis and oedeomatous interdental papillae on this upper right lateral incisor (Fig. 4). Furthermore the bulk of the restoration has resulted in a poor replication of original morphology and consequently is ill fitting within the patient's existing occlusion.

Gold basket crowns can be extended to include bridge like prostheses (Fig. 5), where a pontic is incorporated between two basket crowns to replace missing teeth. Figure 6 shows an example of a bridge prosthesis in situ, which has recently decemented. Distal shadowing is evident on the upper right central incisor indicating extensive underlying caries. Figure 7 shows the abutment teeth without the prosthesis in place. There is poor marginal preparation evident and inadequate approximal reduction distally (11), with no clearance of the contact point. A contribution of these factors along with inadequate oral hygiene habits/diet, has led to marginal leakage. Extensive palatal cavitation was present with caries into the pulp (Fig. 8). There is also gingival recession on both abutment teeth. Due to the unavailability of endodontic therapy, extraction of 11 was the only option for this patient.

Figure 9 shows mesial composite restorations on the upper central incisors. This patient developed caries shortly after gold basket crowns were placed on her central incisors. She was in a position to relocate to the city, where the basket crowns were removed and teeth restored before the teeth became pulpally involved.

\section{COMPARISON TO MODERN DAY RESTORATIONS}

Although the increasing emphasis in modern day restorative dentistry is based around tooth coloured restorations, anterior gold restorations are still being used in popular western cultures. Examples include the use of 'grills' in hip hop culture, which is a dental device made of gold or other metal that may be encrusted with jewels. ${ }^{4}$ This device is removable and therefore has less biological impact than the fixed basket crowns. They carry a similar concept of signifying wealth and status and are usually referred to as tooth jewellery. ${ }^{5}$

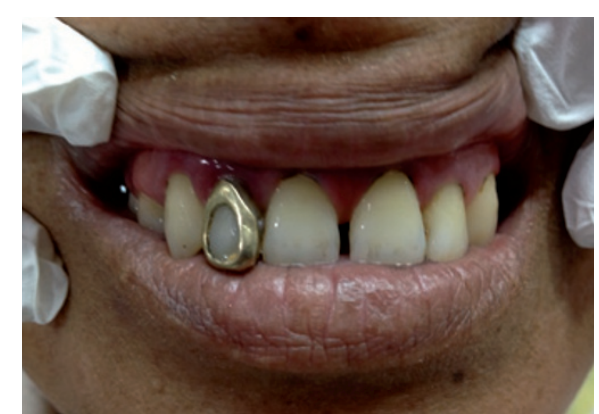

Fig. 4 Gingivitis and oedeomatous interdental papillae on upper right lateral incisor

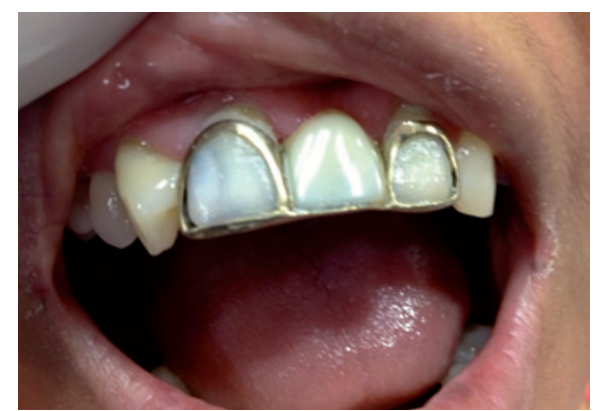

Fig. 6 An example of a bridge prosthesis in situ, which has recently decemented

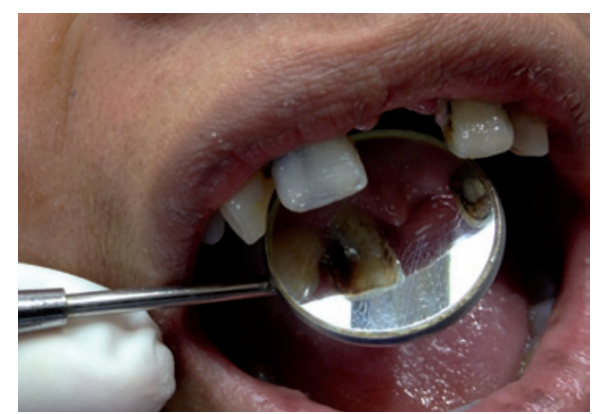

Fig. 8 Extensive palatal cavitation present with caries into the pulp

\section{CONCLUSION}

It can be seen that majority of gold basket crowns are being placed on virgin teeth for cosmetic purposes. Unfortunately, biological implications are a common sequeale following their placement, as can be seen from the selected cases above. With a lack of dental resources and restorative treatment options, the consequence of such resultant caries and periodontal disease means extraction is an inevitable outcome for many of these restored teeth. Aside from signifying status and wealth these crowns may also be placed to maintain tribal identity and group cohesion. ${ }^{6}$ Cultural conformity will mean these anterior

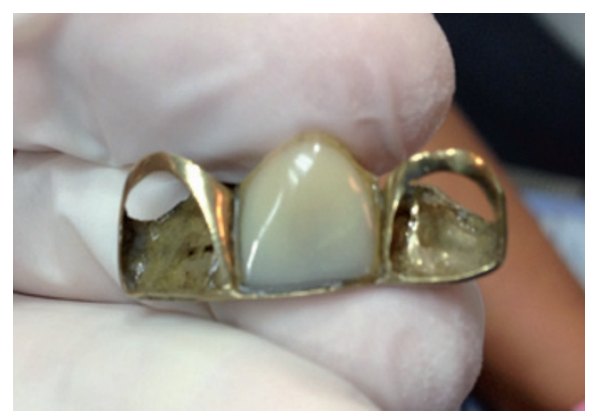

Fig. 5 A bridge like prosthesis gold basket crown

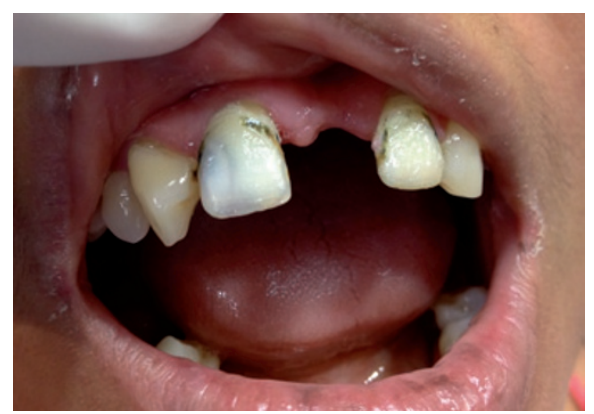

Fig. 7 The abutment teeth without the prosthesis in place

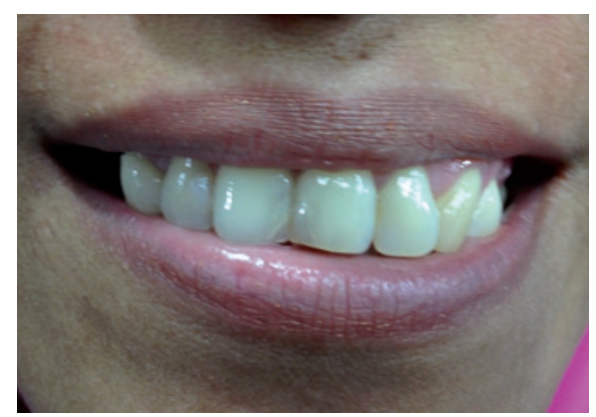

Fig. 9 Mesial composite restorations on the upper central incisors

basket crowns will remain in use for some time to come.

1. Becker M J. Etruscan gold dental appliances: three newly 'discovered' examples. Am J Archaeol 1999; 103: 103-111.

2. Wynbrandt J. The excruciating history of dentistry: toothsome tales and oral oddities from Babylon to braces. New York: St. Martin's Press, 1998.

3. Jones A. Dental transfigurements in Borneo. Br Dent J 2001; 191: 98-102.

4. Hollowell W H, Childers N K. A new threat to adolescent oral health: the grill. Paediatr Dent 2007; 29: 320-322.

5. Scully C. Culturally sensitive oral healthcare. London: Quintessence Publishing Co. Ltd, 2006.

6. Benedix, Derek C. A biocultural analysis of intentional dental modifications. MA thesis, Department of Anthropology. Knoxville: University of Tennessee, 1998. 